\title{
Commentary: Growth of Global Health Spending Share in Low and Middle Income Countries
}

\author{
Ana V. Pejcic* \\ Faculty of Medical Sciences, University of Kragujevac, Kragujevac, Serbia
}

Keywords: global health, health expenditure, medical spending, low-income countries, middle-income countries

\section{A Commentary on}

Growth of Global Health Spending Share in Low and Middle Income Countries by Jakovljevic M, Getzen TE. Front Pharmacol (2016) 7:21. doi:10.3389/fphar.2016.00021

The paper by Jakovljevic and Getzen highlighted the fact that low- and middle-income countries have been grabbing an ever larger share of global health spending over the last couple of decades (1). Share of global health spending of low- and middle-income countries as of 1995 expressed in million current PPP international \$US grew from 26.1\% in 1995 to 39.7\% in 2013 (1). These countries are led by nations of BRICS (Brazil, Russia, India, China, and South Africa), followed by Next-11 nations (Bangladesh, Egypt, Indonesia, Iran, Mexico, Nigeria, Pakistan, the Philippines, Republic of Korea

OPEN ACCESS

Edited by:

Kyriakos Souliotis,

University of Peloponnese, Greece

Reviewed by:

Albert Okunade,

University of Memphis, USA

Athanassios Vozikis,

University of Piraeus, Greece

*Correspondence:

Ana V. Pejcic

anapejcic201502@yahoo.com

Specialty section:

This article was submitted

to Health Economics,

a section of the journal

Frontiers in Public Health

Received: 14 January 2017

Accepted: 28 February 2017

Published: 14 March 2017

Citation:

Pejcic AV (2017) Commentary:

Growth of Global Health Spending

Share in Low and Middle

Income Countries.

Front. Public Health 5:52.

doi: 10.3389/fpubh.2017.00052
(South Korea), Turkey, and Vietnam) with a joint contribution to the global total health expenditure several times below the one of BRICS (1-5). Low- and middle-income countries, which represent an immense range of health system contexts, are likely to have more significant contribution in the global health-care market in the future as it is estimated that per-capita health spending will increase annually by $2.4,3.0$, and $3.4 \%$ in low-, lower-middle-, and upper-middle-income countries by 2040 , respectively $(1,6)$. For high-income countries this rate is estimated at $2.7 \%(6)$.

One interesting question can be raised. What is happening with population health outcomes in low- and middle-income countries as health expenditure is increasing? The authors mentioned that "substantial gains in overall welfare are reflected in the expansion of health insurance coverage and diversity of medical services provided" (1). Some other aspects would also be valuable for discussion.

First, determining the impact of health expenditure on health outcomes is a challenging and complex issue as health outcomes are determined by a vast number of socioeconomic and environmental factors (7-9). Solely increasing public health expenditure, may not significantly affect health outcomes if its efficiency is inadequate $(8,9)$. It has been suggested that, on average, inefficiency of allocating health expenditures in emerging and developing economies is highest in Africa, while Western Hemisphere and Asian economies are relatively more efficient, with significant variations within the aforementioned regions (8). One systematic review has shown that private health-care system sectors in low- and middle-income countries appear to have lower efficiency compared to public sector as a result of weak regulation, higher costs of drugs, improper incentives for unnecessary testing, and treatment, but that, on the other hand, public sector tends to be less responsive to patients and susceptible to the lack of availability of supplies (10). Higher public health expenditure is generally associated with better health outcomes, but still there are substantial differences within the emerging and developing economies groups (8). The relationship between public health expenditure and health-adjusted life expectancy, as well as immunization rates, is generally found to be positive and significant, whereas it is negative and significant with mortality rates (8). For example, favorable effect of higher public 
health expenditure on mortality under 5 years is significantly larger for low- and middle-income countries (11). However, this might not be applicable to all low- and middle-income settings. In some African countries, like Nigeria, increasing public health expenditure alone, without properly addressing issue of corruption, is not enough to lead to improvement in population health status (12).

Health-care quality improvement is very important for improving population health outcomes (13). However, it has been shown that increasing health-care expenditure does not necessarily reflect increasing quality of delivered health care $(14,15)$. The evidence from BRICS nations confirms that sole increase in public health expenditure cannot assure better health outcomes unless the quality of delivered health care is substantially improved (9). Even in the United States, where per-capita spending on health care is estimated to be $50-200 \%$ greater than in other developed countries, this does not yield much better health outcomes compared to other OECD countries (16) and higher spending is not highly correlated with the quality of care, as price of the same service may vary and expensive new therapies may be adopted without good evidence that they improve patient outcomes (17).

In 2012, International Journal for Quality in Health Care dedicated a special issue to address status of health-care quality improvement research in low- and middle-income countries with many papers that highlighted that "much remains to be studied and understood to optimally promote quality improvement" (18). Data on quality of health-care services in low- and middle-income countries are scarce, probably due to the past emphasis on health-care coverage rather than the quality of provided care and insufficient validation of the existing quality measures (19). Quality assessment in terms of infrastructure and staffing, technical quality, and patients' experiences was not done consistently in low- and middle-income countries, thus comparing of measurements made in different settings is difficult (19). A systematic review based on limited data from comparative

\section{REFERENCES}

1. Jakovljevic M, Getzen TE. Growth of global health spending share in low and middle income countries. Front Pharmacol (2016) 7:21. doi:10.3389/ fphar.2016.00021

2. Jakovljevic MM. Comparison of historical medical spending patterns among the BRICS and G7. J Med Econ (2016) 19(1):70-6. doi:10.3111/13696998.2 015.1093493

3. Jakovljevic MB. The key role of the leading emerging BRIC markets in the future of global health care. Serbian J Exp Clin Res (2014) 15(3):139-43. doi:10.2478/SJECR-2014-0018

4. Jakovljevic M, Potapchik E, Popovich L, Barik D, Getzen TE. Evolving health expenditure landscape of the BRICS nations and projections to 2025. Health Econ (2016). doi:10.1002/hec.3406

5. Jakovljevic MB. BRIC's growing share of global health spending and their diverging pathways. Front Public Health (2015) 3:135. doi:10.3389/ fpubh.2015.00135

6. Dieleman JL, Templin T, Sadat N, Reidy P, Chapin A, Foreman K, et al. National spending on health by source for 184 countries between 2013 and 2040. Lancet (2016) 387(10037):2521-35. doi:10.1016/S0140-6736(16) 30167-2 studies conducted in low- and middle-income countries suggested that the quality of private and public ambulatory care is similarly low in terms of infrastructure, clinical competence, and practice for both types of providers, although private sector tends to perform better in drug availability and aspects of delivery of care, such as responsiveness and effort (20).

Increasing burden of rising incidence of non-communicable diseases and accelerated population aging in low- and middleincome countries will pose a major problem for national policy makers (21-29). As Jakovljevic and Getzen pointed out, achievement of universal health coverage, types, and costs of services covered by basic insurance package will certainly remain the major imperatives for national policy makers of these countries (1). Governments will also need a comprehensive approach in order to develop and implement effective strategies to ensure adequate efficiency of forecast increase in health spending along with improving quality of care. Policy lessons from high-income countries may be useful, but they might not transfer well to all low- and middle-income countries' settings due to the key context differences regarding widespread poverty and relative weakness of political and social institutions (15). In order to develop successful approaches, countries should take into consideration their own specific circumstances after careful evaluation and prioritization of underlying problems.

\section{AUTHOR CONTRIBUTIONS}

AP has designed, drafted, and finalized the manuscript.

\section{FUNDING}

AP is awarded with the Scholarship of the Ministry of Education, Science and Technological Development of the Republic of Serbia for Ph.D. students. Publication of results was not contingent to Ministry's censorship or approval.

7. Nixon J, Ulmann P. The relationship between health care expenditure and health outcomes. Evidence and caveats for a causal link. Eur J Health Econ (2006) 7(1):7-18. doi:10.1007/s10198-005-0336-8

8. Grigoli F, Kapsoli J. Waste Not, Want Not: The Efficiency of Health Expenditure in Emerging and Developing Economies. (2013). Available from: https://www. imf.org/external/pubs/ft/wp/2013/wp13187.pdf

9. Kulkarni L. Health inputs, health outcomes and public health expenditure: evidence from the BRICS countries. Int J Appl Econ (2016) 31(1):72-84.

10. Basu S, Andrews J, Kishore S, Panjabi R, Stuckler D. Comparative performance of private and public healthcare systems in low- and middle-income countries: a systematic review. PLoS Med (2012) 9(6):e1001244. doi:10.1371/journal. pmed.1001244

11. Moreno-Serra R, Smith PC. Broader health coverage is good for the nation's health: evidence from country level panel data. J R Stat Soc Ser A Stat Soc (2015) 178(1):101-24. doi:10.1111/rssa.12048

12. Yaqub JO, Ojapinwa TV, Yussuff RO. Public health expenditure and health outcome in Nigeria: the impact of governance. Eur Sci J (2012) 8(13):189-201.

13. Zeng W, Gheorghe A, Nair D. A Discussion Paper of Health System Level Approaches to Addressing Quality of Care in Low-and Middle-Income Countries. (2016). Available from: https://www.rbfhealth.org/sites/rbf/files/ Approaches\%20for\%20Adressing\%20QoC.pdf 
14. Frogner BK, Hussey PS, Anderson GF. Health systems in industrialized countries. In: Glied S, Smith PC, editors. The Oxford Handbook of Health Eonomics. Oxford: Oxford University Press (2011). p. 8-29.

15. Mills A, Hsu J. Health services in low- and middle-income countries: financing, payment, and provision. In: Culyer AJ, editor. Encyclopedia of Health Economics. San Diego: Elsevier (2014). p. 422-34.

16. Anderson GF, Hurst J, Hussey PS, Jee-Hughes M. Health spending and outcomes: trends in OECD countries, 1960-1998. Health Aff (Millwood) (2000) 19(3):150-7. doi:10.1377/hlthaff.19.3.150

17. Burke LA, Ryan AM. The complex relationship between cost and quality in US health care. Virtual Mentor (2014) 16(2):124-30. doi:10.1001/virtualmentor.2014.16.02.pfor1-1402

18. Garcia-Elorrio E, Schneider EC. Research on health-care quality improvement in low- and middle-income countries: is it a worthy investment? Int J Qual Health Care (2012) 24(6):550-2. doi:10.1093/intqhc/mzs067

19. Akachi Y, Tarp F, Kelley E, Addisona T, Kruk ME. Measuring quality-of-care in the context of sustainable development goal 3: a call for papers. Bull World Health Organ (2016) 94(3):160A. doi:10.2471/BLT.16.170605

20. Berendes S, Heywood P, Oliver S, Garner P. Quality of private and public ambulatory health care in low and middle income countries: systematic review of comparative studies. PLoS Med (2011) 8(4):e1000433. doi:10.1371/journal. pmed.1000433

21. Kankeu HT, Saksena P, Xu K, Evans DB. The financial burden from non-communicable diseases in low- and middle-income countries: a literature review. Health Res Policy Syst (2013) 11:31. doi:10.1186/1478-4505-11-31

22. Jakovljevic MB, Milovanovic O. Growing burden of non-communicable diseases in the emerging health markets: the case of BRICS. Front Public Health (2015) 3:65. doi:10.3389/fpubh.2015.00065

23. Ruelas E, Gómez-Dantés O, Leatherman S, Fortune T, Gay-Molina JG. Strengthening the quality agenda in health care in low- and middle-income countries: questions to consider. Int J Qual Health Care (2012) 24(6):553-7. doi:10.1093/intqhc/mzs061

24. Rancic N, Jakovljevic MM. Long term health spending alongside population aging in N-11 emerging nations. Eastern Eur Business Econ J (2016) 2(1):2-6.
25. Jakovljevic MM, Laaser U. Population aging from 1950 to 2010 in seventeen transitional countries in the wider region of South Eastern Europe. SEEJPH (2015) 3. doi:10.12908/SEEJPH-2014-42

26. Marten R, McIntyre D, Travassos C, Shishkin S, Longde W, Reddy S, et al. An assessment of progress towards universal health coverage in Brazil, Russia, India, China, and South Africa (BRICS). Lancet (2014) 384(9960):2164-71. doi:10.1016/S0140-6736(14)60075-1

27. Global Burden of Disease Cancer Collaboration, Fitzmaurice C, Allen C, Barber RM, Barregard L, Bhutta ZA, et al. Global, regional, and national cancer incidence, mortality, years of life lost, years lived with disability, and disability-adjusted life-years for 32 cancer groups, 1990 to 2015: a systematic analysis for the Global Burden of Disease Study. JAMA Oncol (2016). doi:10.1001/jamaoncol.2016.5688

28. GBD 2015 Mortality and Causes of Death Collaborators. Global, regional, and national life expectancy, all-cause mortality, and cause-specific mortality for 249 causes of death, 1980-2015: a systematic analysis for the Global Burden of Disease Study 2015. Lancet (2016) 388(10053):1459-544. doi:10.1016/ S0140-6736(16)31012-1

29. GBD 2015 Disease and Injury Incidence and Prevalence Collaborators. Global, regional, and national incidence, prevalence, and years lived with disability for 310 diseases and injuries, 1990-2015: a systematic analysis for the Global Burden of Disease Study 2015. Lancet (2016) 388(10053):1545-602. doi:10.1016/S0140-6736(16)31678-6

Conflict of Interest Statement: The author declares that the research was conducted in the absence of any commercial or financial relationships that could be construed as a potential conflict of interest.

Copyright (C) 2017 Pejcic. This is an open-access article distributed under the terms of the Creative Commons Attribution License (CC BY). The use, distribution or reproduction in other forums is permitted, provided the original author(s) or licensor are credited and that the original publication in this journal is cited, in accordance with accepted academic practice. No use, distribution or reproduction is permitted which does not comply with these terms. 